\title{
Customer Perceptions of Health Examination Service Quality: An Empirical Investigation in South Korea
}

\author{
Sehwon Kang and Jungsuk Oh
}

\begin{abstract}
With an increasing trend of extended life expectancy and consequential aging society, the demand for health examination is ever heightened. The purpose of this study is to identify the dimensions of health examination service quality and their influence on customer satisfaction and behavioral intention. We utilized a modified SERVPERF model, in which service quality consists of six factors of tangibles, reliability, responsiveness, assurance, empathy, and privacy. Using the structural equation model analysis, we found that six factors of SERVPERF are consolidated into five. Privacy loses its significance, responsiveness and assurance stay valid, and tangibles factor is split into two. Overall, reliability, empathy, and tangibles 1 are found to be the relatively influential to consumer satisfaction.
\end{abstract}

Index Terms-Health examination, health screening, service quality, servperf.

\section{INTRODUCTION}

Health examination service, also referred as health screening, is a multi-phase postural examination that includes chest X-ray examination, blood test, urine test, dental screening and Cancer Screening. It is an outpatient service and has a distinct feature that it provides examination without medical treatment. Reference [1] defined periodic health examination as "a group of tasks designed either to determine the risk of subsequent disease or to identify disease in its early symptomless state".

The importance of periodic health examination had been stressed for more than a century. In 1861, Dr. Horace Dobell, a physician in England, proposed; "There should be instituted, as a custom, a system of periodical examination, to which all persons should submit themselves, and to which they should submit their children" [2]. In 1900, Dr. Gould, an ophthalmologist, also mentioned that "a series of systematized periodic examinations of patients apparently well would often reveal beginning diseases, prevent future illnesses, and increase the vital values of life, everyone can prevail upon certain patients, students, or members of his family, to undergo the necessary tests" [3].

During 1920s, although the National Health Council and the American Medical Association declared in favor of the periodic health examinations for healthy persons, the efficiency and the efficacy of the health examination had been actively debated by professionals until 1970s. After clinical evidences and the promotion of Canadian Task Force

Manuscript received December 16, 2013; revised February 12, 2014.

The authors are with the Seoul National University (SNU), Seoul, Korea (e-mail: joh@snu.ac.kr). and U.S. Preventive Services Task Force, the health examination began to be actively supported by the insurance companies, governments, and each individual [4].

In recent years, extended life expectancy results in aging society, as illustrated in Fig. 1 and Fig. 2, which heightens the necessity of the periodic health examination. Consequently, healthcare cost represents the only expenditure item that increases steadily with age as shown in Fig. 3. The healthcare expenditure repres34ents $9.2 \%$ of the world GDP, $17.4 \%$ of the US GDP, and $11.4 \%$ of Switzerland GDP with a compound annual growth rate of about $4 \%$ in 2000 [5]. In developed countries, the expenditure on cancer and chronic diseases such as hypertension, diabetes, dyslipidemia, and cerebrovascular constitutes a large portion of the total health expenditure [6]. Therefore, an early detection of these diseases saves medical costs and enhances national health level.

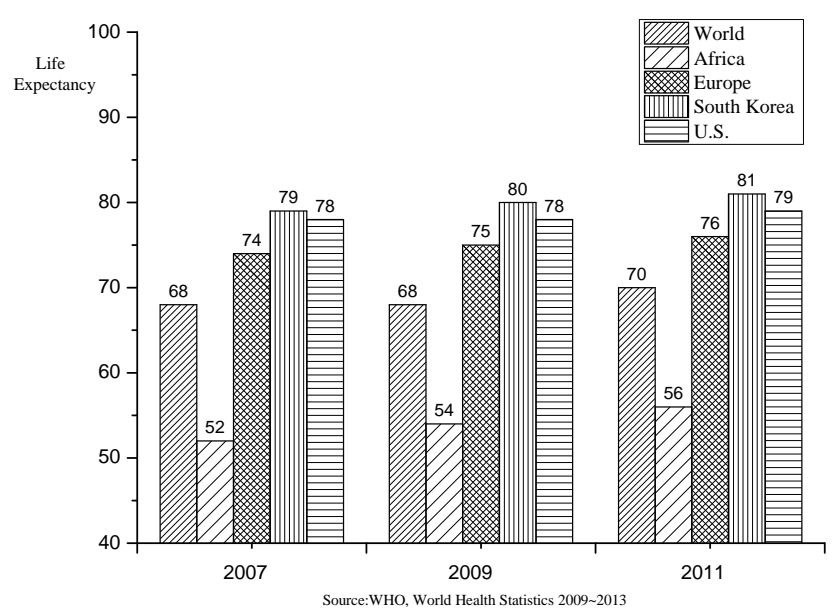

Fig. 1. Trend of global life expectancy.

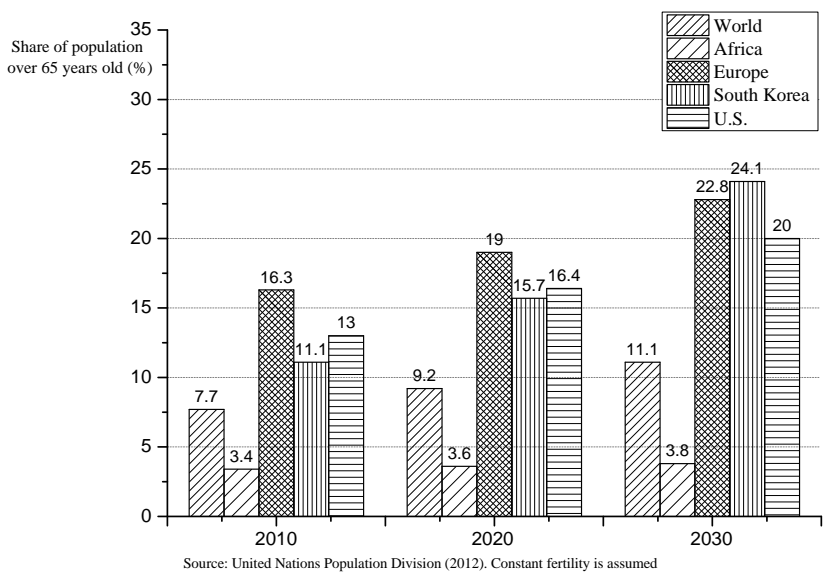

Fig. 2. Proportion of population over 65 years old.

Global expenditure on health is estimated to be 6.98 
trillion USD [7]. However, due to the fact that the expenditure on health examinations is not reported clearly, the global market size of health examination is not attainable. Nevertheless, a few countries provide health examination service through national health screening programs and issue the national report. For instance, the United States runs a program supporting health examinations for age under 21 or over 65 by Medicaid and Medicare. As a result, consumers of other age groups pay their examination fees on their own or through a third party which makes it difficult to estimate the total volume of health examination service. In contrast, the market sizes of the UK and South Korea are attainable. The market size of the UK is $21,496,050$ GBP (USD 34,737,657) and that of South Korea is $813,308,256,000$ KRW (USD $765,106,543)$ in 2011 [8], [9]. The national health screening program of South Korea covered about $20 \%$ of population, or eleven million customers during 2011.

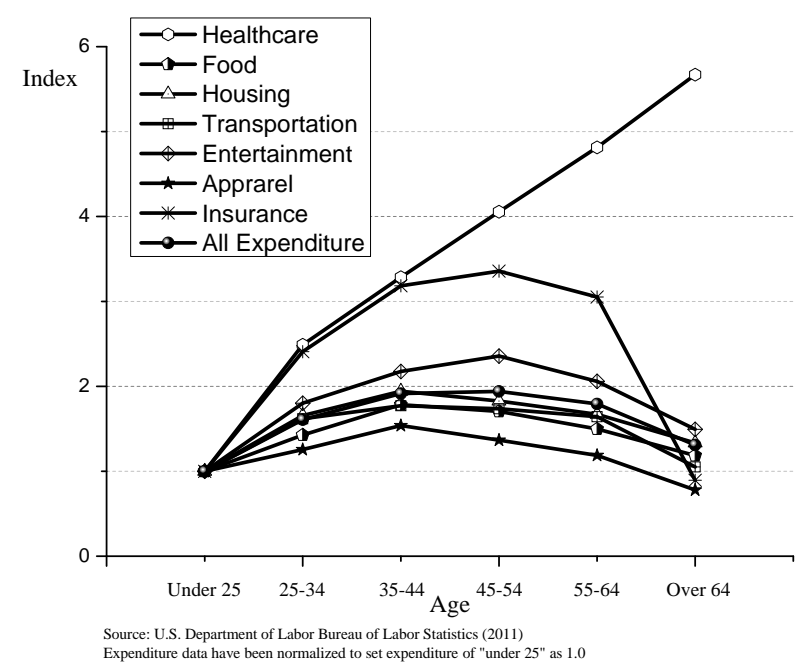

Fig. 3. Health care and other expenditures with age increase

Korea is one of the fastest aging countries in the world. The Korea Institute for Health and Social Affairs recently estimated that average life expectancy will be 87.4 years by 2050. Moreover, Korean Statistical Information Service reported that the ratio between the age group over 65 and under 15 has risen from $20 \%$ in 1990 to $83.3 \%$ in 2013. Table I indicates that the expenditure and the number of examinees of Korean health examination service have increased constantly. It also implies that health screening clinics and centers are more in competition as shown in the growth rate of clinics and centers outweighs the examinee numbers and market.

TABLE I: STATISTICS OF HEALTH EXAMINATION IN KoREA

\begin{tabular}{c|ccrrrrr}
\hline \multicolumn{1}{c|}{20008} & 2009 & 2010 & 2011 \\
\hline \multirow{4}{*}{$\begin{array}{c}\text { Number of } \\
\text { Examinee }\end{array}$} & First & Target & $15,124,755$ & $15,036,607$ & $15,917,939$ & $15,249,528$ \\
& Screening & Examinee & $9,878,548$ & $9,927,538$ & $10,851,277$ & $11,070,569$ \\
\cline { 2 - 7 } & Second & Target & $3,893,203$ & $1,558,511$ & $1,130,883$ & $1,112,233$ \\
& Screening & Examinee & $1,847,391$ & 580,053 & 439,339 & 395,053 \\
\hline Cost & Unit: 1,000 KRW & & $603,982,213$ & $712,078,638$ & $813,308,256$ & $897,766,623$ \\
\hline Centers & & & 5,921 & 6,384 & 7,514 & 8,103 \\
\hline Source: National Health Screening Statistical Yearbook (2011), National Health Insurace Service, Korea
\end{tabular}

In the face of this competition in Korean healthcare industry, each healthcare institute focuses more on consumer-oriented strategy by considering the benefit and utility for consumers [10]. In addition to fundamental benefits for consumers, personal experience and peer recommendations matter the most in the healthcare industry compared to other industries such as hotels, retails, and airlines [11]. Therefore, implementing the right strategy to satisfy consumers is pivotal in healthcare industries. Improving consumer satisfaction is mostly related to enhancing service quality perceived by consumers and the first step to enhance service quality is the identification of the determinants of service quality [12].

However, consumer satisfaction and quality dimensions of health examination service have not been actively researched. Existing researches on health examination takes the perspective of public health or medical science. Representative topics include effectiveness of health examination in the local community [13], [14] and the factors affecting examination rate [18]. Although there are some researches on service quality or consumer satisfaction of health examination, they are either exploratory [15], [16] or incomplete [17], [18] due to the ignorance of reliability and validity factors. Since different service areas of hospitals are considered separately [19], specific research efforts on the health examination service quality is needed.

\section{LITERATURE REVIEW}

Historically, the definition of healthcare quality is mostly based on the resulting condition of health. This quality has been defined as "the ability to achieve desirable objectives using legitimate means" and the desirable objective means "an achievable state of health" [20]. Institute of Medicine defines it as "the extent to which health services provided to individuals and patient populations improve desired health outcomes". The Joint Commission on Accreditation of Healthcare Organizations defines it as "the degree to which patient care services increase the probability of desired outcomes and reduce the probability of undesired outcomes given the current state of knowledge" [21]. In sum, healthcare quality has been defined in terms of technical delivery of care by physician's viewpoint. However, recent literatures on healthcare quality question the validity of using the technical quality and instead, emphasize the importance of the patient's perceived quality and satisfaction [22], [23].

Service quality consists of technical quality and functional quality. The former involves what the customer is actually receiving from the service and the latter involves the manner in which the service is delivered [24]. In healthcare service, functional quality is gaining more importance than technical quality [25], [26]. This is due to the fact that consumers can evaluate subjective quality more easily than technical quality. In general, most patients do not know whether the service was performed properly or even necessary [23], [27]. Healthcare service is also characterized by significant time lag between provider's provision of service and patient's perception of technical quality [23]. Hence, functional quality is usually the primary determinant of patients' quality perceptions. With these considerations, the focus of the health service quality shifts from professionals' view of 
technical quality to consumers' view of subjective quality [28].

SERVQUAL methodology has become primary tool for measuring "functional service quality" in service industries including health care services [22], [29]-[31]. SERVQUAL is based on the expectancy disconfirmation model [32], which states that evaluation of service quality by comparing the gap between prior expectations of what the service should provide and perception of service received [33]-[35]. SERVQUAL has been extensively employed in healthcare service research including acute care [36], physicians' service [37], nursing service [38], [39], cancer center [22], and maternity hospitals [40] in numerous countries as shown in Table II. Many literatures have pointed out the need for measuring quality expectations in SERVQUAL. SERVQUAL measures the expectation of consumers after the service. Hence, the expectation may be biased by the memory of actual services received [41]. In this regard, using SERVQUAL to measure prior expectation and perception can lead to inaccuracy [29], [42], [43]. Additionally, in the context of the healthcare service, many patients are not sure about what to expect from the healthcare service [44].

TABLE II: RESEARCH OF HEALTHCARE SERVICE QuALity (T: TANGIBLES, R: RELIABILITY, R: RESPONSIVENESS, A: ASSURANCE, E: EMPATHY)

\begin{tabular}{|c|c|c|c|c|c|c|c|}
\hline \multirow[t]{2}{*}{ Research } & \multirow[t]{2}{*}{ Service Context } & \multirow[t]{2}{*}{ Perceived by } & \multicolumn{5}{|c|}{ Dimensions } \\
\hline & & & $T$ & $\mathrm{R}$ & $\mathrm{R}$ & $\bar{A}$ & $\bar{E}$ \\
\hline $\begin{array}{l}\text { Jun and Zsidisin } \\
\text { (1998) }\end{array}$ & US hospitals & \begin{tabular}{l|} 
Patients, \\
physicians, \\
administrators
\end{tabular} & 0 & 0 & 0 & & \\
\hline$\overline{O^{\prime} \text { Connor (2000) }}$ & US hospitals & \begin{tabular}{l|} 
Physicians, \\
administrators \\
,employees
\end{tabular} & 0 & 0 & 0 & 0 & 0 \\
\hline$\overline{\text { Lee et al. (2000) }}$ & US hospitals & Physicians & 0 & 0 & 0 & O & o \\
\hline $\begin{array}{l}\text { Reidenbach and Sandifer- } \\
\text { Smallwood (1990) }\end{array}$ & US hospitals (emergency rooms) & $\begin{array}{c}\text { Patients } \\
\text { Pans }\end{array}$ & & & & & \\
\hline$\overline{\operatorname{Carman}(1990)}$ & US dental clinics & Patients & $\mathrm{O}$ & 0 & & & \\
\hline Babakus and Mangold (199. & US hospitals, Hong Kong's hospitals & Patients & & & & & \\
\hline$\overline{\operatorname{Dean}(1999)}$ & Australia, medical/health care & Patients & 0 & O & O & 0 & o \\
\hline $\begin{array}{l}\text { Anderson and Zwelling } \\
\text { (1996), Chaniotakis and } \\
\text { Lymperopoulos(2009) }\end{array}$ & $\begin{array}{l}\text { US Cancer center, Greek maternity } \\
\text { hospitals, respectively }\end{array}$ & Patients & 0 & 0 & 0 & 0 & 0 \\
\hline $\begin{array}{l}\text { Moon et al. (1998), Han et } \\
\text { al. (2007), } \\
\text { Kim et al. (2011) }\end{array}$ & $\begin{array}{l}\text { Korean public health center or } \\
\text { hospitals }\end{array}$ & Patients & 0 & 0 & 0 & 0 & 0 \\
\hline Lim and Tang $(2000)$ & Singapore, general and special clinics & Patients & 0 & 0 & 0 & O & o \\
\hline$\overline{\text { Andaleeb (2001) }}$ & Bangladesh hospitals & Patients & & & 0 & 0 & \\
\hline$\overline{\text { Ramsaran-Fowdar(2008) }}$ & Mauritian hospitals, General Physicians & Patients & 0 & 0 & 0 & 0 & 0 \\
\hline Choe et al. (2012) & Korean hospitals & Patients & 0 & & & & $\bar{O}$ \\
\hline Choi et al. (2004) & Korean hospitals & Outpatients & 0 & & & & \\
\hline $\begin{array}{l}\text { Pakdil and Harwood (2005) } \\
\text { (20rw }\end{array}$ & US, Anesthesia service & Inpatients & & & & & \\
\hline Kara et al. (2005) & Turkish hospitals & Inpatients & 0 & 0 & 0 & 0 & $\bar{O}$ \\
\hline Kim and Park (2006) & Korean hospitals & $\begin{array}{l}\text { Inpatie } \\
\text { nts }\end{array}$ & 0 & 0 & D & 0 & 0 \\
\hline$\overline{\text { Zineldin (2006) }}$ & Egyptian and Jordanian hospitals & Inpatients & & & & & \\
\hline
\end{tabular}

two $\bullet$ dimensions converged to a single dimension

* Indicates the factors from PZB (1985), bold indicates factor added by author

Ref. [42] Investigated conceptualization and measurement of service quality and the relationships among service quality, consumer satisfaction and purchase intentions. They strongly advised that performance determines service quality in lieu of the gap between performance and expectation. SERVPERF, an alternative methodology to SERVQUAL, appears to have a good fit and more construct-valid explication of service quality [42], [45]. SERVPERF is also actively employed in the context of healthcare services [45]-[47].

In terms of technical quality, healthcare service quality consists of dimensions such as efficacy, effectiveness, efficiency, legitimacy, optimality, acceptability, and equity [48]. Similarly, WHO suggested dimensions such as effectiveness, efficiency, accessibility, acceptable/patient centered, equitable, and safety. In contrast, many recent literatures focus on functional quality measured by SERVQUAL, SERVPERF, or their variants. SERVQUAL introduces five dimensions of tangibles, reliability, responsiveness, assurance, and empathy [34], which is also shared by SERVPERF. The description of each of these five dimensions is shown in the following [33]. The relevant researches on quality dimensions of healthcare service are shown in Table II.

The different functions or service areas within hospitals should be considered and measured separately [19], [36], [46]. In that respect, researches regarding health examination service and its quality dimensions are necessary [49]. However, many of current researches are either exploratory or flawed in some ways. In Table III, some researchers introduce dimensions without focus group interview or corresponding literature study [50] and others have problems in terms of reliability and validity investigation [17], [18].

TABLE III: RESEARCH ON HEALTH EXAMINATION SERVICE QUALITY

\begin{tabular}{lll}
\hline Author & Dimensions & Remark \\
\hline Kim and Ryu (2001) & $\begin{array}{l}\text { Examination, Excellent facilities, } \\
\text { Expenses }\end{array}$ & reliability and validity were not investigated \\
Lee and Jung (2006) & $\begin{array}{l}\text { User environment, Process, } \\
\text { Result consultation }\end{array}$ & reliability and validity were not investigated \\
NHIC (2007) & Communication, Attitude, Privacy, & reliability and validity did not met the \\
& Environment, Exam result & academic standard \\
Cha (2011) & Tangibles, Reliability, & Responsiveness, \\
& Assurance, Empathy & reliability and validity were not investigated \\
\hline
\end{tabular}

Privacy or confidentiality during transactions emerged as a critical attribute during the focus group interview in the context of banking and securities brokerage services, belonging to the security dimension [33]. In healthcare service, patients' perception of privacy attribute strongly affects satisfaction [51]. The importance of privacy attribute has been pointed out in various contexts such as primary care [52], and emergency room [51], [53]. Privacy also appears as a tangibles factor in other healthcare literature [36], [54], [55].

In health examination service research, privacy sometimes is considered as a dimension or an item belonging to other dimensions. For instance, [17] concedes that privacy dimension consists of two items of disclosure of body during examination process and respect of privacy. [18] maintains that two privacy items in health examination belongs to different dimensions, respectively. The item of privacy respect belongs to tangibles and the respect of secret belongs to assurance. However, the former research is seriously unsatisfying in terms of the academic standard of reliability and validity and the latter one is implemented without investigation of reliability and validity. Therefore, further research on the privacy dimensions or items is required.

We assume health examination service consists of six quality dimensions from previous literature study, adding privacy dimension to five dimensions of SERVQUAL/SERVPERF. We hypothesize that each dimension has positive effect on consumer satisfaction.

H1: Tangibles has a positive effect on the satisfaction level 
of the health examination service.

H2: Reliability has a positive effect on the satisfaction level of the health examination service.

H3: Responsiveness has a positive effect on the satisfaction level of the health examination service.

H4: Assurance has a positive effect on the satisfaction level of the health examination service.

H5: Empathy has a positive effect on the satisfaction level of the health examination service.

H6: Privacy has a positive effect on the satisfaction level of the health examination service.

Ref. [32] defined consumer satisfaction as "the summary psychological state resulting when the emotion surrounding disconfirmed expectations is coupled with the consumer's prior feelings about the consumption experience." Patient satisfaction, the consumer satisfaction in healthcare context, is an indicator of quality of health care from the patient's perspective [56]. As a valid indicator of healthcare outcome, high patient satisfaction should result in revisiting [23], [57] and recommending to others [19], [23]. In that respect, impact on these behavioral intentions has been actively researched in health care industries [19], [23], [57].

H7: Patient satisfaction affects behavior intentions positively (revisit and recommend).

\section{RESEARCH DESIGN AND METHODOLOGY}

$\mathrm{H} 1$ : Tangibles has a positive effect on satisfaction of using health examination.

H2: Reliability has a positive effect on satisfaction of using health examination.

H3: Responsiveness has a positive effect on satisfaction of using health examination.

H4: Assurance has a positive effect on satisfaction of using health examination.

H5: Empathy has a positive effect on satisfaction of using health examination.

H6: Privacy has a positive effect on satisfaction of using health examination.

H7: Patient satisfaction positively affects behavior intentions.

We use structural equation model (SEM) for identifying the hypothesis. The use of SEMs is more precise in specification of hypotheses and provides construct validity in broader and deeper ways than traditional analyses [58].

Since an appropriate adaptation of the instrument is desirable for investigating a specific service [34], [36], we have tried to reflect specific consideration of the health examination service environment. Our questionnaire is based on SERVQUAL [34] and other researches in the domain of healthcare service. We have incorporated results from pilot studies and consulting by professionals in family medicine and business into the compilation of suitable measurement items for the survey. As a result, we extracted 32 items from literature study and made adjustment for the health examination service context. We utilized results of [29], [36], and [55] as major references. Since the health examination service provider of our choice offers service with no charge, items regarding cost ([22], [29], [36], [54], [59]) have been removed. Also, since consumers of health examination service are treated as outpatients, the items pertinent to inpatients have been excluded. These include discharge process [19], [36] and meal ([19], [36], [55]). The finalized items and their references are depicted in Table V (See Fig. 4).

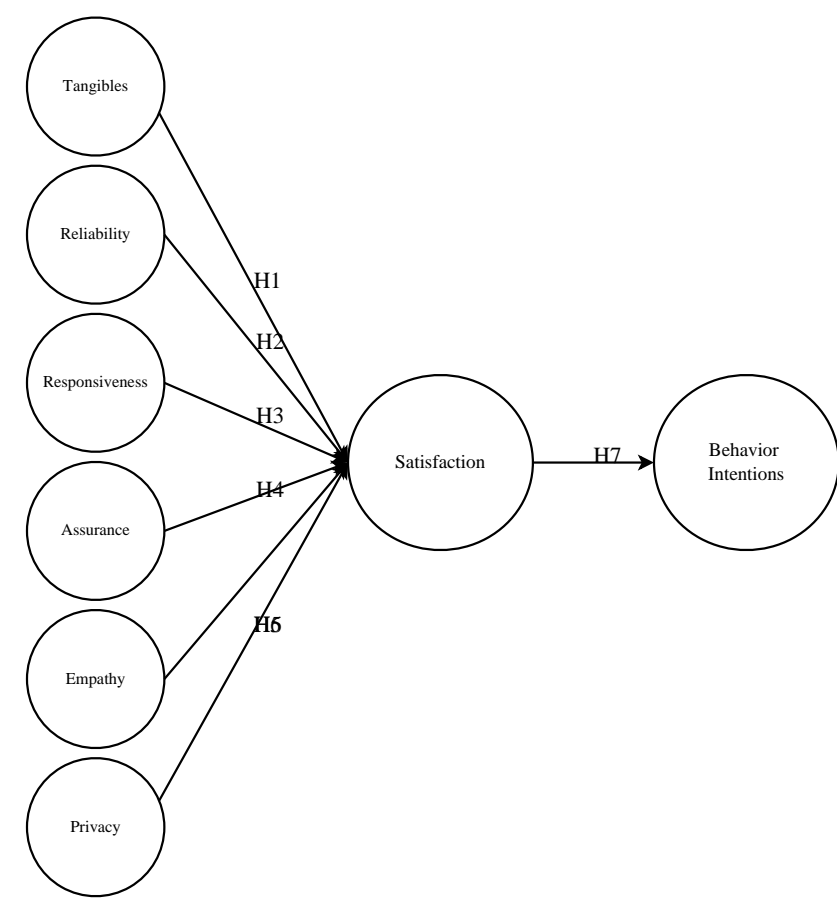

Fig. 4. Main model.

TABLE IV: ITEMS AND DIMENSIONS

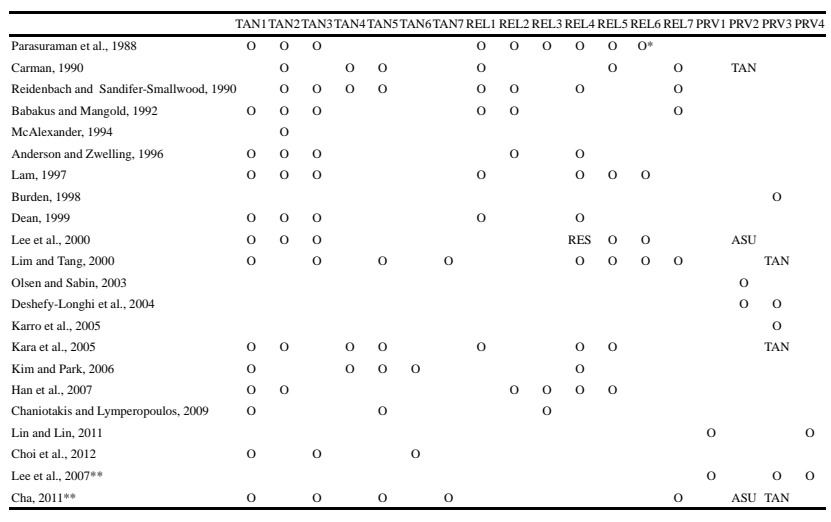

TABLE V: ITEMS AND DIMENSIONS - CONT'D

\begin{tabular}{|c|c|c|c|c|c|c|c|c|c|c|c|c|c|c|}
\hline & RES1 & RES2 & RES3 & RES & RES5 & RES6ASU & 1ASU2. & $2 \mathrm{ASU} 3$ & BASU4. & 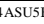 & EMP1 & $\mathrm{MP2}$ & $\mathrm{MP3}$ & EMP4 \\
\hline Parasuraman et al., 1988 & $\bar{O}$ & o & $\mathrm{o}$ & $\mathrm{O}$ & & $\mathrm{O}$ & $\mathrm{O}$ & $\mathrm{O}$ & & & $\mathrm{O}$ & $\mathrm{o}$ & o & $\mathrm{O}$ \\
\hline Carman, 1990 & o & o & o & o & & o & o & o & & RES & & o & & \\
\hline Reidenbach and Sandifer-Smallwood, 1990 & & & & & & o & & o & & o & & o & & \\
\hline Babakus and Mangold, 1992 & o & o & o & & & & o & o & o & 0 & & & o & \\
\hline McAlexander, 1994 & & & o & & & o & o & o & & & & & & 0 \\
\hline Anderson and Zwelling, 1996 & $\mathrm{o}$ & o & o & & & & $\mathrm{o}$ & $\mathrm{o}$ & o & & o & & o & \\
\hline Lam, 1997 & o & o & o & o & & o & o & o & & & o & o & o & o \\
\hline Dean, 1999 & o & o & & o & & & o & o & & & & & & o \\
\hline Lee et al., 2000 & & & & & & & & o & & RES & & o & & RES \\
\hline Lim and Tang, 2000 & & o & & o & & & & o & o & o & & o & o & o \\
\hline Kara et al., 2005 & & o & o & & & o & o & o & & RES & & o & & \\
\hline Kim and Park, 2006 & & & & & ASU & & & EMP & & o & & & & \\
\hline Han et al., 2007 & & o & o & & & o & o & & o & & o & o & o & o \\
\hline Chaniotakis and Lymperopoulos, 2009 & & o & & & & & & o & o & o & & o & o & \\
\hline Cha, 2011** & & o & & o & o & & & o & o & EMP & & & & \\
\hline Choi et al., 2012 & & & & & & & & & TAN & EMP & & o & & \\
\hline
\end{tabular}

Review of measurement items was based on the pre-test and responses from professionals. Pre-test of an instrument is an integral part of the survey construction [60], which gives feedbacks to the researcher and introduces potential 
problems with the survey [61]. For this reason, pre-test is actively used in quality studies of healthcare service ([22], [29], [40]). The survey questionnaires were distributed to five outpatients, who had recently experienced health examination service for invaluable feedback. Some survey items were changed or removed as participants found them confusing or impossible to answer. For instance, ASU4 was deleted since consumers may not contact doctors to ask questions. EMP6 also was removed because some respondents claimed that answering both EMP1 and EMP6 are redundant.

TABLE VI: DEMOGRAPHICS $(N=136)$

\begin{tabular}{|c|c|c|c|}
\hline & & Freequency & Percent (\%) \\
\hline Gender & (3 missings) & & \\
\hline Male & & 65 & 48.9 \\
\hline Female & & 68 & 51.1 \\
\hline Age & (4 missings) & & \\
\hline Under 30 & & 28 & 21.2 \\
\hline $30 \sim 39$ & & 40 & 30.3 \\
\hline $40 \sim 49$ & & 37 & 28.0 \\
\hline $50 \sim 59$ & & 23 & 17.4 \\
\hline Over 59 & & 4 & 3.0 \\
\hline Marriage & (3 missings) & & \\
\hline Yes & & 93 & 30.1 \\
\hline No & & 40 & 69.9 \\
\hline \multicolumn{4}{|c|}{ Education (3 missings) } \\
\hline Middle sch & hool & 1 & 0.8 \\
\hline High scho & & 31 & 23.3 \\
\hline Bachelor's & Degree & 93 & 69.9 \\
\hline Graduate I & Degree & 8 & 6.0 \\
\hline \multicolumn{4}{|c|}{ Physical Cor (3 missings) } \\
\hline Bad & & 1 & 0.8 \\
\hline Average & & 58 & 43.6 \\
\hline Good & & 73 & 54.9 \\
\hline Other & & 1 & 0.8 \\
\hline \multicolumn{4}{|c|}{ Chronic Dist (3 missings) } \\
\hline Yes & & 8 & 6.0 \\
\hline No & & 125 & 94.0 \\
\hline \multicolumn{4}{|c|}{ Knowledge (3 missings) } \\
\hline Bad & & 19 & 14.3 \\
\hline Average & & 101 & 75.9 \\
\hline Good & & 13 & 9.8 \\
\hline \multicolumn{4}{|c|}{ Experience ( 3 missings $)$} \\
\hline Yes & & 60 & 45.1 \\
\hline No & & 73 & 54.9 \\
\hline Place & (3 missings) & & \\
\hline A & & 85 & 63.9 \\
\hline B & & 48 & 36.1 \\
\hline
\end{tabular}

After the pre-test, we collected feedbacks from two professionals in family medicine and one in business administration. PRV4 was deleted since the response will not be achievable. We collected the survey right after the consumers received the service but collecting responses for PRV4 took additional 10 days and further contact was impossible due to the privacy act. REL6 was changed slightly due to confusion. Lastly, two instruments of behavior intentions and survey design of color were changed for easier identification.

Contrary to seven-point Likert scale, we employed five-point Likert scale, $(1$ = strongly disagree, 5=strongly agree), since seven-point Likert scale can be confusing under certain circumstances ([29]). In addition, negatively worded items were not used because of response quality problem ([29], [36]).

The data for the study were obtained from a paper-based survey questionnaire. The survey had been collected for two weeks from two healthcare centers in Seoul. 201 consumers were asked to complete the survey and the response rate was $62.4 \%$ to result in the total of 136 valid responses that were free of missing items or skewed responses. There was no significant pattern or trend regarding missing items.

\section{DATA ANALYSIS, INTERPRETATION AND RESULTS}

Demographic statistics are displayed in Table V. Physical condition is a subjective condition that the patient feels. Knowledge indicates the self evaluation of one's knowledge of health. Experience means whether consumer has experience of health examination service at the same healthcare center. Place A or B indicates the specific location of the health care center. Table VI indicates that the sample mainly consists of consumers with high level of academic degrees.

TABLE VII: EXPLORATORY FACTOR ANALYSIS

\begin{tabular}{|c|c|c|c|c|c|c|c|}
\hline \multirow{2}{*}{$\begin{array}{c}\text { Items in } \\
\text { each } \\
\text { dimension }\end{array}$} & \multicolumn{5}{|c|}{ Factor Loadings } & \multicolumn{2}{|c|}{ Reliability Index } \\
\hline & Tangibles 1 & Tangibles 2 & Reliability & $\begin{array}{l}\text { Responsive } \\
\text { Assurance }\end{array}$ & Empathy & $\begin{array}{l}\text { Item-to-total } \\
\text {-correlation }\end{array}$ & $\begin{array}{c}\text { Cronbach's } \\
\alpha\end{array}$ \\
\hline Tangibles 1 & & & & & & & 0.818 \\
\hline TAN1 & 0.846 & & & & & 0.692 & \\
\hline TAN2 & 0.828 & & & & & 0.692 & \\
\hline Tangibles 2 & & & & & & & 0.803 \\
\hline TAN3 & & 0.573 & & 0.496 & & 0.614 & \\
\hline TAN4 & & 0.812 & & & & 0.650 & \\
\hline TAN5 & & 0.718 & & 0.417 & & 0.723 & \\
\hline Reliability & & & & & & & 0.834 \\
\hline REL2 & & & 0.707 & 0.362 & 0.338 & 0.735 & \\
\hline REL3 & & & 0.657 & & 0.368 & 0.663 & \\
\hline REL6 & & & 0.535 & 0.422 & & 0.698 & \\
\hline Res./Assu. & & & & & & & 0.961 \\
\hline RES2 & & 0.308 & 0.358 & 0.673 & & 0.857 & \\
\hline RES3 & & & & 0.804 & 0.364 & 0.875 & \\
\hline RES4 & & & & 0.802 & 0.341 & 0.899 & \\
\hline RES5 & & & & 0.735 & & 0.811 & \\
\hline ASU1 & & & 0.383 & 0.676 & 0.370 & 0.894 & \\
\hline ASU2 & & 0.348 & 0.461 & 0.600 & 0.316 & 0.864 & \\
\hline ASU3 & & & & 0.744 & & 0.835 & \\
\hline Empathy & & & & & & & 0.926 \\
\hline EMP1 & & & & 0.345 & 0.760 & 0.826 & \\
\hline EMP2 & & & 0.310 & & 0.794 & 0.840 & \\
\hline EMP3 & & & & & 0.851 & 0.903 & \\
\hline EMP4 & & & & & 0.799 & 0.760 & \\
\hline PRV2 & & & & 0.449 & 0.719 & 0.740 & \\
\hline
\end{tabular}

The factor analysis, which is useful in establishing reliability and validity in empirical research methods [60], was utilized to investigate reliability and validity. For purification process, we followed the sequence of [34] and [23]. The exploratory factor analysis was carried with principal component analysis and Varimax rotation. During the process, the instruments and factors were rearranged. First, we found out that tangibles factor was divided into two. One factor consists of TAN1 and TAN2 and the other does TAN3, TAN4, and TAN5. Responsiveness and assurance 
emerged as one dimension and privacy items are absorbed into empathy. Items TAN7, ASU4, and PRV1 were deleted by step 1. Then, TAN6, REL1, REL5, REAL7, RES1, RES6, EMP5, and PRV3 were deleted by step 4. Deleted items are poorly correlated or associated with more than a single factor considerably.

TABLE VIII: CONFIRMATORY FACTOR ANALYSIS

\begin{tabular}{llllll}
\hline Items in dimension & & Loadings & AVE*>.5 AVE**.5 & CR >.6 \\
\hline Tangibles 1 & & & 0.824 & 0.695 & 0.903 \\
TAN1 & up-to-date equipment & 0.797 & & & \\
TAN2 & facilities visually appealing & 0.869 & & & \\
Tangibles 2 & & & 0.797 & 0.922 & 0.600 \\
TAN3 & employees well dressed and neat & 0.764 & & & \\
TAN4 & convenient and comfortable facilities & 0.736 & & & \\
& & & & \\
TAN5 & clean and comfortable environment & 0.821 & & & \multirow{2}{*}{0.923} \\
Reliability & & & 0.800 & 0.633 & \\
REL2 & sympathetic and reassuring & 0.814 & & & \\
REL3 & dependable center & 0.749 & & & \\
REL6 & performs right at the first time & 0.822 & & & \\
Res./Assu. & & & 0.902 & 0.780 & 0.985 \\
RES2 & prompt service from employees & 0.852 & & & \\
RES3 & willing to help customers & 0.894 & & & \\
RES4 & respond customer requests promptly & 0.914 & & & \\
RES5 & proper waiting time & 0.828 & & & \\
ASU1 & can trust employees & 0.911 & & & \\
ASU2 & feel safe in your interaction & 0.894 & & & \\
ASU3 & polite employees & 0.886 & & & \\
Empathy & & & 0.809 & 0.733 & 0.955 \\
EMP1 & gives individual attention & 0.854 & & & \\
EMP2 & know what your needs are & 0.903 & & & \\
EMP3 & has your best interests at heart & 0.944 & & & \\
EMP4 & convenient operating hours & 0.797 & & & \\
PRV2 & keep customer's secret & 0.771 & & & \\
\hline
\end{tabular}

*Fornell and Larcker (1981), **Hair et al. (2006).

TABLE IX: DISCRIMINANT VALIDITY

\begin{tabular}{lccccc}
\hline Correlations & AVE* & AVE** & $\Phi$ & $\Phi^{2}$ & Validity \\
\hline Tangibles $1 \Leftrightarrow$ Tangibles2 & 0.824, & $0.695,0.922$ & 0.678 & 0.460 & $\mathrm{O}$ \\
& 0.797 & & & & \\
Tangibles $1 \Leftrightarrow$ Reliability & 0.824, & $0.695,0.633$ & 0.623 & 0.388 & $\mathrm{O}$ \\
& 0.800 & & & & \\
Tangibles $1 \Leftrightarrow$ Responsiveness/Assurance & 0.824, & $0.695,0.780$ & 0.618 & 0.382 & $\mathrm{O}$ \\
& 0.902 & & & & \\
Tangibles $1 \Leftrightarrow$ Empathy & 0.824, & $0.695,0.733$ & 0.493 & 0.243 & $\mathrm{O}$ \\
Tangibles2 $\Leftrightarrow$ Reliability & 0.809 & & & \\
Tangibles2 $\Leftrightarrow$ Responsiveness/Assurance & $0.797,0.8000 .922,0.633$ & 0.776 & 0.602 & $\mathrm{O}$ \\
Tangibles2 $\Leftrightarrow$ Empathy & $0.797,0.8090 .922,0.780$ & 0.856 & 0.733 & $\mathrm{O}$ \\
Reliability $\Leftrightarrow$ Responsiveness/Assurance & $0.800,0,9020.633,0.780$ & 0.599 & 0.874 & 0.764 & $\mathrm{O}$ \\
Reliability $\Leftrightarrow$ Empathy & $0.800,0.8090 .633,0.733$ & 0.774 & 0.599 & $\mathrm{O}$ \\
Responsiveness/Assurance $\Leftrightarrow$ Empathy & $0.902,0.8090 .780,0.733$ & 0.751 & 0.564 & $\mathrm{O}$ \\
\hline
\end{tabular}

*Fornell and Larcker (1981), **Hair et al. (2006).

Individual item reliability, the composite reliability for latent variables, and the average variance extracted $(A V E)$ were analyzed. The reliability test result satisfies as it meet the each standard of item-to-total correlations $(A V E>0.3)$ [62], Cronbach's alpha ( $\alpha>0.7)$, Average Variance Extracted $(A V E>0.5)$, and Composite Reliability $(C R>0.6)$ [58] as reported in Table VII and Table VIII.

Several types of validity such as construct validity, convergent validity and discriminant validity can serve as criteria for assessing scale [35]. To assess the validity of the measures, factor analysis results were employed. Although the exploratory factor analysis indicates that TAN3 (0.573) and REL6 (0.535) have somewhat low factor loadings, the confirmatory analysis supports all the items satisfy the critical level of .7. In practice, factor loadings as low as .50 still can satisfy the overall SEM model, thus researcher should focus on hypotheses and goodness-of-fit [58]. The value of AVE, 0.633 0.922, and the one of CR, 0.600 0.955, in Table VIX imply that this model has convergent validity. Lastly, discriminant validity was also confirmed. Table $\mathrm{X}$ shows that the correlation between one scale and another is not as high as each scale's coefficient by comparing AVE and $\Phi^{2}$.

Modified measurement model is followed by the previous analysis and finally has five dimensions of tangibles 1, tangibles 2, reliability, responsiveness/assurance, and empathy. The overall fit of measurement model and main model are good as shown in Table X. Although $\chi^{2}$ test of each model is significant, the sensitivity of $\chi^{2}$ test has potential problems in sample size. As the sample size increases, the chances of rejecting a model also increase [63].

TABLE X: GOODNESS-OF-FIT INDICES

\begin{tabular}{lccccccc}
\hline & $\chi^{2}$ & DF & $\chi^{2} /$ DF & RMSEA & IFI & TLI & CFI \\
\hline surement M & 323.769 & 160 & 2.024 & 0.074 & 0.936 & 0.923 & 0.935 \\
Main Model & 618.583 & 446 & 1.387 & 0.054 & 0.941 & 0.928 & 0.94 \\
\hline *DF stands for degree of freedom
\end{tabular}

H1-1. Tangibles 1 has a positive effect on the satisfaction level of the health examination service.

Accepted $(P=0.017)$

H1-2. Tangibles 2 has a positive effect on the satisfaction level of the health examination service.

Rejected

H2. Reliability has a positive effect on the satisfaction level of the health examination service.

Accepted $(P<0.001)$

$\mathrm{H} 3 / \mathrm{H} 4$. Responsiveness/assurance has a positive effect on the satisfaction level of the health examination service.

Rejected

H5. Empathy has a positive effect on the satisfaction level of the health examination service.

Accepted $(P<0.001)$

H6. Privacy has a positive effect on the satisfaction level of the health examination service.

Not available

H7: Satisfaction level positively affects behavior intention. Accepted $(P<0.001)$

The noticeable result is that the tangibles dimension is divided into two dimensions. This result coincides with previous research of Parasuraman et al., [35]. They found that the four items under tangibles consistently break into two factors, with Q1 and Q2 (equipment and physical facilities) forming one factor, and Q3 and Q4 (employees and communication materials) forming another factor. We have similar results that TAN1 and TAN2 (equipment and physical facilities) comprise Tangibles 1 and TAN3, TAN4, and TAN5 (employees and communication materials) comprise Tangibles 2 . In addition, only tangibles 1 related to equipment and physical facilities were found to be significant factor in influencing consumer satisfaction in health examination service.

Another result is that responsiveness and assurance dimensions are converged as one dimension. The exploratory 
factor analysis shows considerable overlap between two factors and the confirmatory factor analysis supports that treating these two dimensions as one satisfies the reliability and the validity. As Parasuraman et al., [35] indicated, assurance of willing to assist customers can be related to the perception of responsiveness. Other healthcare service researches using SERVQUAL or its variant also report considerably high correlations between reliability and responsiveness [64], assurance and empathy [65], and responsiveness and empathy [66] as shown in Table II. Our study introduces another context of convergence between two factors in which responsiveness and assurance show significant correlationm (See Fig. 5).

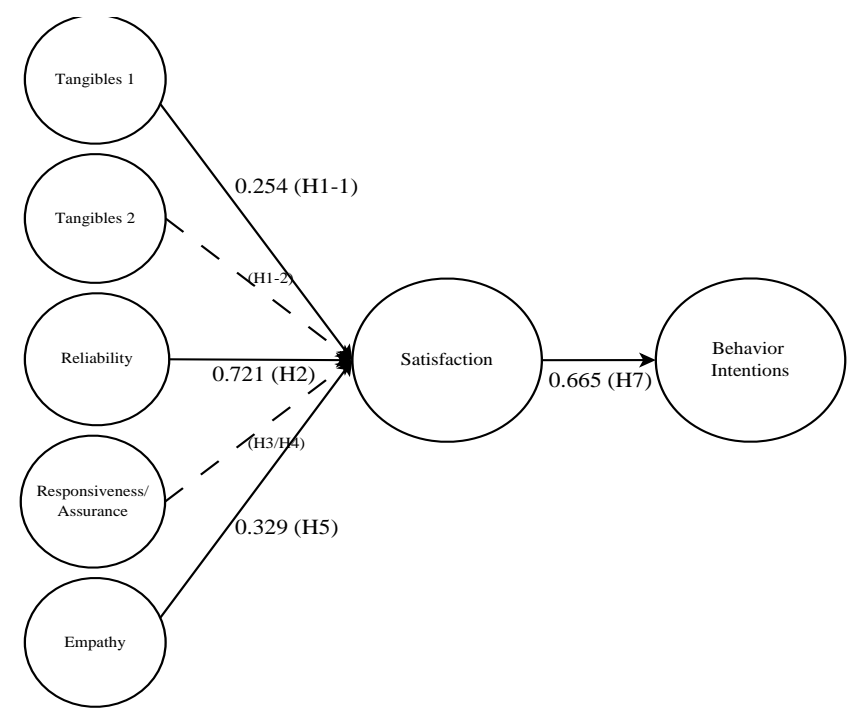

Fig. 5. Main model (modified).

In search of new dimension pertaining to the specific service category of healthcare examination ([36], [49]), we introduces privacy as the sixth dimension with four measurement items. However, PRV4 was deleted from the feedback of professionals, PRV1 was rejected due to lack of contribution to improving the total-item-correlation, and PRV3 was trimmed due to the high cross-ladings with other dimensions of responsiveness/assurance (0.533) and empathy (0.603). As a result, a single item, PRV2, cannot construct the dimension. This cast doubt on the research of NHIC ([17]), in which it was conceded that privacy in health examination service emerges as an important one from the focus group interview. However, due to unsatisfactory reliability and the validity results, we claim that privacy may not construct a dimension in health examinations service.

The relative importance of each dimension on customer satisfaction in health examination service is readily observable. Though responsiveness/assurance and tangibles 2 are not significant, reliability (0.721), empathy (0.329), and tangibles 1(0.254) are found to be significant. This result implies that reliability is the most important dimension, followed by empathy and tangibles 1 . Also, the impact of satisfaction on revisit $(0.610)$ turns out to be slightly more significant than that on recommendation (0.541).

\section{CONCLUSION}

The purpose of this research is to identify the quality dimensions of health examination service and their impacts on consumer satisfaction and behavior intentions. Although previous researches have dealt with various healthcare service contexts, the health examination service has been received much attention.

Several interesting findings emerged from this study. First, we found that privacy does not construct the dimension. This contradicts the former research in health examination service [17] and supports the view of other healthcare service research that privacy is employed as measurement item. Second, responsiveness and assurance dimensions are merged as one, which supports the result by [35], [67]. Third, tangibles dimension is split into two, supporting [35]. Tangibles 1, equipment and physical facilities, affect consumer satisfaction and tangibles 2, employees and communication materials, does not. This result is in line with that from [35] and revisits the previous result of [36] that dress (TAN3) is not an important item in the hospital setting. Lastly, the relative importance of reliability and empathy dimensions implies that health examination centers have to focus on these two dimensions to effectively improve consumer satisfaction.

It has been suggested that very few indicators per factor may produce unstable solutions and thus, some researchers claim to use at least three indicators per factor [58]. Therefore, one of the limitations of this research is that both tangible 1 and behavior intention have only two indicators. Another limitation is that our sample contains similar characteristics. We tried to investigate the impact of chronic disease on consumer satisfaction by group analysis, but only 8 consumers had chronic diseases.

Since the sample covers two health examination centers in Seoul, South Korea, further research on more diverse samples with various culture and location is desirable. We investigated the impact of physical condition, medical knowledge and other elements on consumer satisfaction by group analysis, but there is no significant difference. We assumed that this result derives from the rather homogeneous nature of the sample.

During the purification process, items such as ASU5, the explanation item, had significant cross loadings. As depicted in Table IV, it appears to be in different dimensions such as responsiveness or empathy in healthcare service. In this respect, we need further research to determine whether the explanation compose a new dimension or belongs to previous SERVQUAL dimension.

\section{REFERENCES}

[1] Canadian Task Force on the Periodic Health Examination, "The periodic health examination," Canadian Medical Association Journal, vol. 121, no. 9, pp. 1193-254, 1979.

[2] H. Dobell, "Lectures on the germs and vestiges of disease: and on the prevention of the invasion and fatality of disease by periodical examinations," Delivered at the Royal Infirmary for Diseases of the Chest, John Churchill, 1861.

[3] G. M. Gould, "A System of personal biologic examinations the condition of adequate medical and scientific conduct of life," JAMA, vol. 35, no. 3, pp. 134-138, 1990.

[4] H. G. Seo, "Periodic health examination in its historical perspectives," Korean Journal of Medical History, vol. 8, no. 1, pp. 79-89, 1999.

[5] OECD. (2011). Health at a glance 2011: OECD Indicators. [Online] Available: http://dx.doi.org/10.1787/health_glance-2011-en 
[6] World Economic Forum. (2011). The Global Economic Burden of Non-communicable Diseases. [Online]. Available: http://www.weforum.org/reports

[7] WHO. (2013). World Health Statistics 2013. [Online]. Available: http://www.who.int/gho/publications/world_health_statistics/2013/en/

[8] UK National Screening Committee. (2012). Screening in England 2011-12. [Online]. http://www.screening.nhs.uk/publications/

[9] National Health Insurance Service (NHIS), 2011 National Health Screening Statistical Yearbook, National Health Insurance Corporation, Seoul, 2012.

[10] Samsung Economic Research Institute (SERI), "Healthcare 3.0," CEO Information, vol. 831, pp. 1-23, 2011.

[11] Pricewaterhouse Coopers (PwC). (2012). Customer Experience in Healthcare: The Moment of Truth. [Online]. Available: http://www.pwc.com/us/en/health-industries/publications/health-carecustomer-experience.jhtml

[12] R. Johnston, "The determinants of service quality: satisfiers and dissatisfiers," International Journal of Service Industry Management, vol. 6, no. 5, pp. 53-71, 1995.

[13] H. Iwasa, H. Yoshida, H. Kim, Y. Yoshida, J. Kwon, M. Sugiura, and T. Suzuki, "A mortality comparison of participants and non-participants in a comprehensive health examination among elderly people living in an urban Japanese community," Aging Clinical and Experimental Research, vol. 19, no. 3, pp. 240-245, 2007.

[14] R. C. Gwynn, R. K. Garg, B. D. Kerker, T. R. Frieden, and L. E. Thorpe, "Contributions of a local health examination survey to the surveillance of chronic and infectious diseases in New York City," American Journal of Public Health, vol. 99, no. 1, pp. 152-159, 2009.

[15] R. Nupponen, "Client views on periodic health examinations: opinions and personal experience," Journal of Advanced Nursing, vol. 23, no. 3, pp. 521-527, 1996.

[16] Y. Shin, C. Y. Park, S. H. Jung, H.Y. Jung, and H. Kang, "Comparison of customer satisfaction with health examination programs provided by the Korea National Health Insurance and private healthcare organizations in Korea," Journal of Korean Society of Quality Assurance in Health Care, vol. 12, no. 1, pp. 40-51, 2005.

[17] National Health Insurance Corporation (NHIC), Survey on the Satisfaction of Health Screening Examinees and Perception of Non-Examinees, National Health Insurance Corporation, Seoul, 2007.

[18] W. S. Cha, "Satisfaction of medical check-up examinee using servqual," MPH Thesis, Kosin University, 2001.

[19] R. E. Reidenbach and B. S. Smallwood, "Exploring perceptions of hospital operations by a modified SERVQUAL approach," Journal of Health Care Marketing, vol. 10, no. 4, pp. 47-55,1990.

[20] A. Donabedian, Explorations in Quality Assessment and Monitoring: the Definition of Quality and Approaches to Its Assessment, The Criteria and Standards of Quality, Health Administration Press, Ann Arbor, MI, 1982.

[21] R. Fromberg, Monitoring and Evaluation in Patient Care Services, Joint Commission on Accreditation of Healthcare Organizations, Chicago, 1998.

[22] E. Anderson and L. Zwelling, "Measuring service quality at the University of Texas M.D. Anderson Cancer Centre," International Journal of Health Care Quality Assurance, vol. 9, no. 7, pp. 9-22, 1996.

[23] K. Choi, W. Cho, S. Lee, H. Lee, and C. Kim, "The relationships among quality, value, satisfaction and behavioral intention in health care provider choice: a South Korean study," Journal of Business Research, vol. 57, no. 8, pp. 913-921.

[24] C. Grönroos, "Innovative marketing strategies and organization structures for service firms," Emerging Perspectives on Services Marketing, American Marketing Association, Chicago, IL, pp. 9-21, 1993.

[25] M. M. Yasin and R. F. Green, "A strategic approach to service quality: a field study in a rural health care setting," Health Marketing Quarterly, vol. 13, no. 1, pp. 75-85, 1996.

[26] M. Jun, R. T. Peterson, and G. A. Zsidisin, "The identification and measurement of quality dimensions in health care: focus group interview results," Health Care Management Review, vol. 23, no. 4, pp. 81-96, 1998.

[27] F. Pakdil and T. N. Harwood, "Patient satisfaction in a preoperative assessment clinic: an analysis using SERVQUAL dimensions," Total Quality Management and Business Excellence, vol. 16, no. 1, pp. 15-30, 2005.

[28] S. S. Andaleeb, "Service quality perceptions and patient satisfaction: a study of hospitals in a developing country," Social Science and Medicine, vol. 52, no. 9, pp. 1359-1370, 2001.
[29] E. Babakus and W. G. Mangold, "Adapting the SERVQUAL scale to hospital services: an empirical investigation," Health Service Research, vol. 26, no. 6, pp. 767-786, 1992.

[30] S. S. Lam, "SERVQUAL: a tool for measuring patients' opinions of hospital service quality in Hong Kong," Total Quality Management, vol. 8, no. 4, pp. 145-152, 1997.

[31] S. J. O'Connor, H. Q. Trinh, and R. M. Shewchuk, "Perceptual gaps in understanding patient expectations for health care service quality", Health Care Management Review, vol. 25, no. 2, pp. 7-23, 2000.

[32] R. L. Oliver, "Measurement and evaluation of satisfaction processes in retail settings," Journal of Retailing, vol. 57, no. 3, pp. 25-48, 1981.

[33] A. Parasuraman, V. A. Zeithaml, and L. L. Berry, "A conceptual model of service quality and its implications for future research," The Journal of Marketing, vol. 49, no. 4, pp. 41-50, 1985.

[34] A. Parasuraman, V. A. Zeithaml, and L. L. Berry, "Servqual," Journal of Retailing, vol. 64, no. 1, pp. 12-40, 1998

[35] A. Parasuraman, V. A. Zeithaml, and L. L. Berry, "Refinement and reassessment of the SERVQUAL scale," Journal of Retailing, vol. 67 , no. 4 , pp. $420-450,1991$

[36] J. M. Carman, "Consumer perceptions of service quality: an assessment of the SERVQUAL dimensions," Journal of Retailing, vol. 66, no. 1, pp. 33-55, 1990

[37] S. W. Brown and T. A. Swartz, "A gap analysis of professional service quality," Journal of Marketing, vol. 53, no. 4, pp. 92-98, 1989.

[38] S. A. Scardina, "SERVQUAL: a tool for evaluating patient satisfaction with nursing care," Journal of Nursing Care Quality, vol. 8, no. 2, pp. 38-46, 1994.

[39] Ö. Uzun, "Patient satisfaction with nursing care at a university hospital in Turkey," Journal of Nursing Care Quality, vol. 16, no. 1, pp. 24-33, 2001.

[40] I. E. Chaniotakis and C. Lymperopoulos, "Service quality effect on satisfaction and word of mouth in the health care industry," Managing Service Quality, vol. 19, no. 2, pp. 229-242, 2009.

[41] S. S. Andaleeb and A. K. Basu, "Technical complexity and consumer knowledge as moderators of service quality evaluation in the automobile industry," Journal of Retailing, vol. 70, no. 4, pp. 367-381, 1994.

[42] S. A. Taylor, "Measuring service quality: a reexamination and extension," Journal of Marketing, vol. 56, no. 3, pp. 55-68, 1992.

[43] A. R. Hubbert, A. G. Sehorn, and S. W. Brown, "Service expectations: the consumer versus the provider," International Journal of Service Industry Management, vol. 6, no. 1, pp. 6-21, 1995.

[44] R. Fitzpatrick and A. Hopkins, "Problems in the conceptual framework of patient satisfaction research: an empirical exploration," Sociology of Health and Illness, vol. 5, no. 3, pp. 297-311, 1983.

[45] J. H. McAlexander, D. O. Kaldenberg, and H. F. Koenig, "Service quality measurement," Journal of Health Care Marketing, vol. 14, no. 3, pp. 34-40, 1994

[46] S. Han, I. Son, J. Gu, and S. Lee, "The study on the effect of health care service quality upon customer loyalty: Based upon SERVPERF," Journal of the Korean Society for Quality Management, vol. 35, no. 1, pp. 61-72, 2007.

[47] M. Holder and A. Berndt, "The effect of changes in servicescape and service quality perceptions in a maternity unit," International Journal of Health Care Quality Assurance, vol. 24, no. 5, pp. 389-405, 2011.

[48] A. Donabedian, Explorations in Quality Assessment and Monitoring: the Definition of Quality and Approaches to its Management, Health Administration Press, Ann Arbor, 1980.

[49] J. Chung and J. Han, "The effects of the attribute-level satisfaction on the overall satisfaction and the mediation role of involvement in medical service," Korean Corporation Management Review, vol. 16 no. 2, pp. 243-258, 2009.

[50] Y. S. Lee and M. S. Jung, "The effects of the customer satisfaction of general health examination service on their revisiting intention and change of health belief, self-efficacy and health promoting behavior," Journal of Korean Academy of Nursing Administration, vol. 12, no. 1, pp. 94-103, 2006.

[51] Y. K. Lin and C. J. Lin, "Factors predicting patients' perception of privacy and satisfaction for emergency care," Emergency Medicine Journal, vol. 28, no. 7, pp. 604-648, 2001.

[52] T. D. Longhi, J. K. Dixon, D. Olsen, and M. Grey, "Privacy and confidentiality issues in primary care: views of advanced practice nurses and their patients," Nursing Ethics, vol. 11, no. 4, pp. 378-393, 2004.

[53] J. Karro, A. W. Dent, and S. Farish, "Patient perceptions of privacy infringements in an emergency department," Emergency Medicine Australasia, vol. 17, no. 2, pp. 117-123, 2005. 
[54] P. C. Lim and N. K. Tang, "A study of patients' expectations and satisfaction in Singapore hospitals," International Journal of Health Care Quality Assurance, vol. 13, no. 7, pp. 290-299, 2001.

[55] A. Kara, S. Lonial, M. Tarim, and S. Zaim, "A paradox of service quality in Turkey," European Business Review, vol. 17, no. 1, pp. 5-20, 2005.

[56] C. Campen, H. Sixma, R. D. FrieZe, J. J. Kerssens, and L. Peters, "Quality of care and patient satisfaction: a review of measuring instruments," Medical Care Research and Review, vol. 52, no. 1, pp. 109-133, 1995.

[57] A. G. Woodside, L. L. Frey, and R. T. Daly, "Linking service quality, customer satisfaction, and behavioral intention," Journal of Health Care Marketing, vol. 9, no. 4, pp. 5-17, 1989.

[58] R. P. Bagozzi and Y. Yi, "On the evaluation of structural equation models," Journal of the Academy of Marketing Science, vol. 16, no. 1, pp. 74-94,1998.

[59] T. S. Dagger, J. C. Sweeney, and L. W. Johnson, "A hierarchical model of health service quality: scale development and investigation of an integrated model," Journal of Service Research, vol. 10, no. 2, pp. 123-142, 2007.

[60] B. B. Flynn, S. Sakakibara, R. G. Schiroeder, K. A. Bates, and E. J. Fylnn, "Empirical research methods in operations management," Journal of Operations Management, vol. 9, no. 2, pp. 250-284, 1990.

[61] H. K. Moss, The Application of the Theory of Constraints in Service Firms, Doctoral dissertation, Clemson University, 2002.

[62] J. C. Nunnally, Psychometric Theory, McGraw-Hill, New York, NY, 1978.

[63] R. P. Bagozzi and Y. Yi, "Specification, evaluation, and interpretation of structural equation model," Journal of the Academy of Marketing Science, vol. 40, no. 1, pp. 8-34, 2012.

[64] A. M. Dean, "The applicability of SERVQUAL in different health care environments," Health Marketing Quarterly, vol. 16 no. 3, pp. 1-21, 1999.

[65] R. R. R. Fowdar, "The relative importance of service dimensions in a healthcare setting," International Journal of Health Care Quality Assurance, vol. 21, no. 1, pp. 104-124, 2008.
[66] M. Kim and H. Park, "An empirical study on service quality and patien satisfaction in specialty and general hospitals," Korean Journal of Hospital Management, vol. 11, no. 1, pp. 31-53, 2006.

[67] H. Lee, L. M. Delene, M. A. Bunda, and C. Kim, "Methods of measuring health-care service quality," Journal of Business Research, vol. 48, no. 3, pp. 233-246, 2000

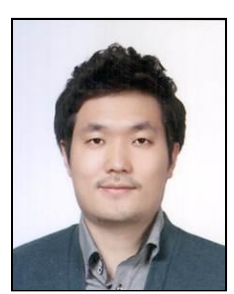

Sehwon Kang is a master's student at the Business School, Seoul National University (SNU), Seoul, Korea. He was born in Seoul, Korea in 1984. His primary research interests are Quality Management and Healthcare Management. He received his bachelor's degree in electrical engineering from SNU.

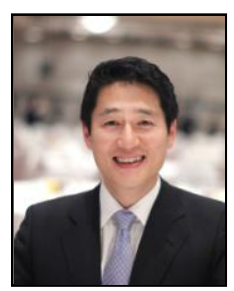

Jungsuk Oh is an associate professor at the Business School, Seoul National University (SNU), Seoul, Korea. He was born in Port Jefferson, NY, U.S.A. in 1970. His primary research interests are Telecom/Media/IS Economics, Cooperative Game Theory, Platform/Ecosystem Strategy, Quality Management and Servitization. He has been a professor at SNU since 2007. Before then, he was a professor at the Business School, Korea Advanced Institute of Science and Technology (KAIST) since 2003. He received his master's and Ph.D. degrees in management science and engineering from Stanford University. He received his bachelor's degree in management science from Massachusetts Institute of Technology (MIT). He has published several books in the areas of applications of game theory, high-technology and mobile industries, technology management and management science. 